\title{
TRATAMENTO DOS RESERVATÓRIOS DE ÁGUA DO PERÍMETRO RURAL DA CIDADE DE PINHALZINHO/SC
}

Raquel Bulegon ${ }^{1}$

Andreia Zamiani ${ }^{2}$

\section{Gilmar de Almeida Gomes ${ }^{3}$}

RESUMO: O aumento populacional tem como consequência o uso crescente dos recursos naturais, na maioria das vezes de forma irracional, trazendo como consequência grandes desequilíbrios ambientais. Os recursos hídricos estão sofrendo várias formas de contaminação, podendo gerar impactos tanto nas águas subterrâneas como nas superficiais. O objetivo do presente estudo foi avaliar a qualidade da água de 11 pontos do perímetro rural do município de Pinhalzinho, oeste do estado de Santa Catarina. Os métodos utilizados foram análises microbiológicas (coliformes fecais e totais) e físico-químicas (cloreto, condutividade elétrica, $\mathrm{pH}$, sólidos e turbidez). A avaliação das análises mostrou que todos os pontos possuem algum resultado fora dos padrões estabelecidos, sendo que o ponto 9, Linha Santa Terezinha, apresentou relativa relevância pois apresentou os maiores índices para coliformes fecais (16 NMP/100 ml), coliformes totais ( $>16 \mathrm{NMP} / 100 \mathrm{ml}$ ) e turbidez ( 1,52 UNT), concluindo que o monitoramento e tratamento destas águas é uma necessidade urgente.

Palavras-chave: Água, recursos naturais, sustentabilidade.

\footnotetext{
${ }^{1}$ Acadêmico(a) de Engenharia de Alimentos, Universidade do Estado de Santa Catarina. raquelbuligon@hotmail.com.

${ }^{2}$ Acadêmico(a) de Engenharia de Alimentos, Universidade do Estado de Santa Catarina. deia_zamiani@hotmail.com.

${ }^{3}$ Dr. em Química, Profo da Universidade do Estado de Santa Catarina. gilmargomess@yahoo.com.br.
} 


\section{INTRODUÇÃO}

O modelo econômico atual baseado na exploração dos recursos naturais vem trazendo graves desequilíbrios no meio ambiente. Desta forma é preciso ter como objetivo central, antes de tudo preservar e conserva-lo.

A maior parte dos danos ambientais tem relação com ações antropogênicas, ou seja, aquelas causadas pelo homem, como por exemplo: o aumento nas emissões de dióxido de carbono, causando o efeito estufa, desmatamento, queimadas e a destruição de ecossistemas. (CAMPONOGARA, 2012).

A água é o recurso natural mais abundante no planeta; porém, água com qualidade adequada para o consumo humano já se tornou um problema (MAYER, 2010). A ameaça de escassez desse recurso tem colocado a água no centro das disputas e preocupações em todo o mundo. (SOUZA, 2012).

Portanto, a adoção de medidas para a conservação e o uso racional da água, a utilização de fontes alternativas e a criação de políticas públicas de educação ambiental para a conscientização da população sobre a necessidade de se preservar esse recurso natural são de fundamental importância para assegurar a disponibilidade a atual e as futuras gerações. (SOUZA, 2012).

As fontes de contaminação da água são em geral associadas a dejetos domésticos, indústrias e agrotóxicos; são inúmeras as impurezas que se apresentam nas águas naturais como, por exemplo, os vírus, bactérias, parasitas e substâncias tóxicas. (RICHTER, 1991).

È imprescindível o tratamento desta água, trazendo melhores condições higiênicas (remoção de bactérias, protozoários e outros microorganismos, redução de impurezas e do teor de compostos orgânicos) e estéticas (cor, odor e sabor). (RICHTER, 1991).

Pelo fato da água ser um assunto de estrema importância no meio ambiente, é necessário estudos e avaliações sobre sua qualidade estimulando ações de controle ambiental. 
O município de Pinhalzinho possui muitas nascentes de água doce espalhadas por toda sua extensão. Estas nascentes são utilizadas para todas as atividades familiares inclusive alimentação, exigindo uma atenção especial.

O objetivo do presente estudo é verificar a qualidade da água dos reservatórios comunitários da zona rural, através de análises microbiológicas (coliformes totais e fecais) e físico-químicas ( $\mathrm{pH}$, condutividade elétrica $(\mathrm{CE})$, turbidez, sólidos, cloreto).

\section{MATERIAIS E MÉTODOS}

\section{1. Área de estudo}

Na Figura 1 são representados os pontos de coletas, todos situados no perímetro rural. Cada ponto indica um reservatório, na área rural, da qual foram coletados amostras de água para análise. A numeração das linhas foi estabelecida aleatoriamente, pois, buscava-se verificar quais parâmetros estavam em conformidade, portanto as linhas sempre apresentam o mesmo número.

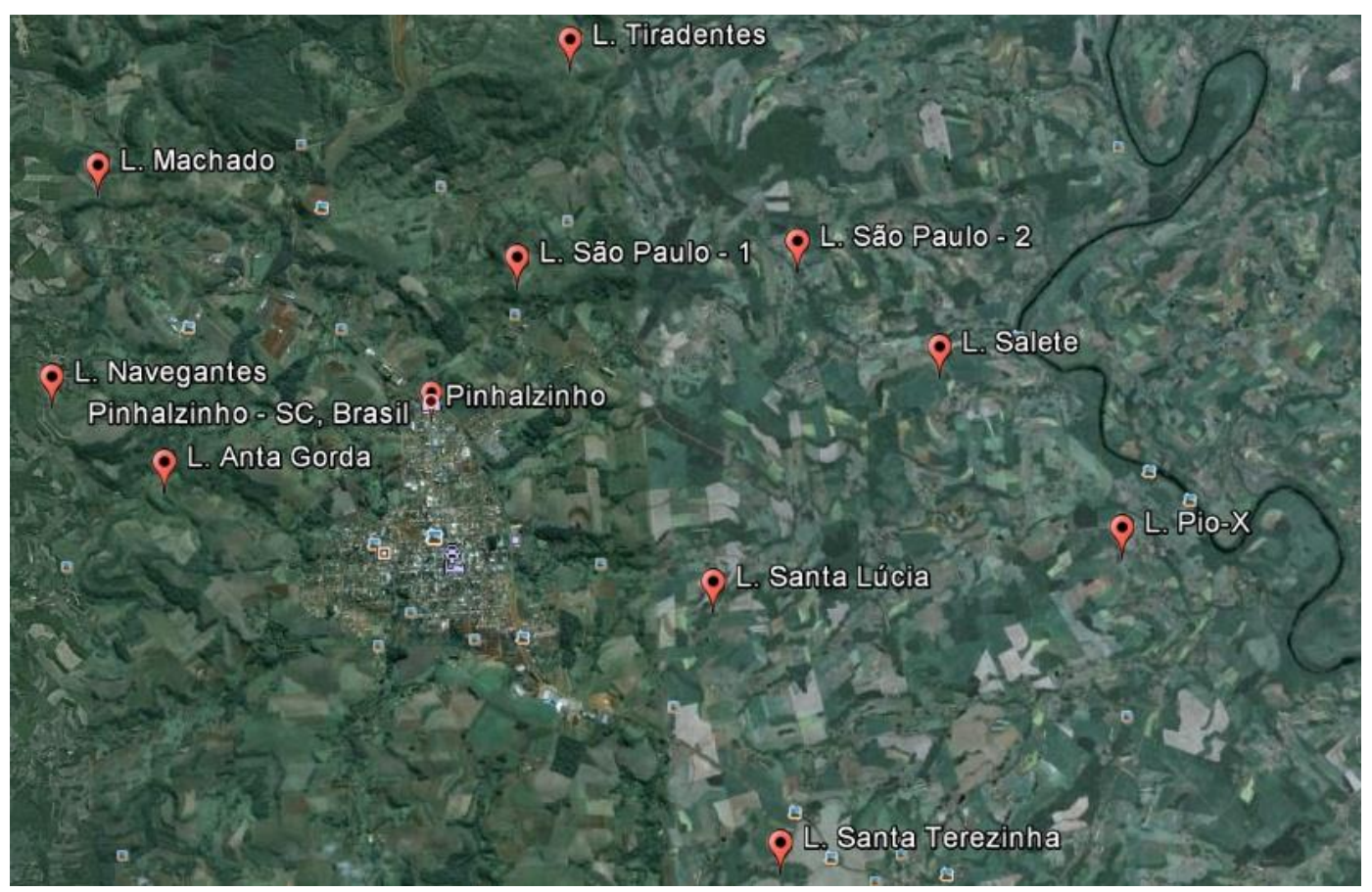

Figura 1. Pontos de coleta de água no município de Pinhalzinho/SC, todos situados no perímetro rural. 
Na Tabela 1 são apresentadas as coordenadas destas fontes.

Tabela 1. Coordenadas das fontes analisadas.

\begin{tabular}{ccc}
\hline FONTE & S & WO \\
\hline L. Santa Lúcia & $26^{\circ} 51.409^{\prime}$ & $52^{\circ} 57.635^{\prime}$ \\
L. Pio-X & $26^{\circ} 51.200^{\prime}$ & $52^{\circ} 55.273^{\prime}$ \\
L. Machado & $26^{\circ} 49.056^{\prime}$ & $53^{\circ} 01.050^{\prime}$ \\
L. Salete & $26^{\circ} 50.283^{\prime}$ & $52^{\circ} 56.294^{\prime}$ \\
L. São Paulo -1 & $26^{\circ} 49.589^{\prime}$ & $52^{\circ} 58627^{\prime}$ \\
L. São Paulo-2 & $26^{\circ} 49.678^{\prime}$ & $52^{\circ} 57.085^{\prime}$ \\
L. Tiradentes & $26^{\circ} 48.525^{\prime}$ & $52^{\circ} 58.336^{\prime}$ \\
L. Navegantes & $26^{\circ} 50015^{\prime}$ & $53^{\circ} 01.499^{\prime}$ \\
L. Santa Terezinha & $26^{\circ} 52.729^{\prime}$ & $52^{\circ} 57.445^{\prime}$ \\
L. Anta Gorda & $26^{\circ} 50.923^{\prime}$ & $53^{\circ} 01.222^{\prime}$ \\
\hline
\end{tabular}

\subsection{Metodologia}

Foram coletadas 11 amostras de água entre junho e agosto de 2012 (uma em cada fonte), as quais foram armazenadas em recipientes próprios de $500 \mathrm{ml}$, mantidos numa caixa de isopor até a chegada ao laboratório.

Para as determinações de cloreto, coliformes totais e fecais e sólidos seguiram-se os métodos descritos pelo Manual Prático de Análise de Água da FUNASA (Fundação Nacional de Saúde).

Na medida de $\mathrm{pH}$ foi utilizado o pHmetro (Q400 MT) da marca Quimis, a turbidez foi determinada através do equipamento MSTECNOPON (TB 1000P), enquanto a CE foi determinada pelo condutivímetro AZ 8351 da marca QUIMIS. 


\section{RESULTADOS E DISCUSSÕES}

$\mathrm{Na}$ Tabela 2, é apresentado os resultados obtidos nas coletas para coliformes totais, coliformes fecais, cloreto, $\mathrm{pH}$, condutividade elétrica, turbidez e sólidos, para os 11 pontos de coleta.

Para uma melhor visualização, os resultados experimentais também se apresentam na forma de gráficos, Figura 3 a Figura 9. Evidente que o parâmetro linha, eixo $X$ do gráfico não é uma grandeza quantitativa, porém, todos eles apresentam a mesma sequência possibilitando uma análise comparativa, por exemplo: quais linhas têm os maiores valores da variável analisada, quais linhas apresentam valores de não conformidade, etc.

Tabela 2. Resultados de coliformes totais, coliformes fecais, cloreto, $\mathrm{pH}$, condutividade elétrica, turbidez e sólidos, para os 11 pontos de coleta.

\begin{tabular}{cccccccc}
\hline FONTE & $\begin{array}{c}\text { Coliformes } \\
\text { Totais } \\
(\mathbf{N M P / 1 0 0 m l})\end{array}$ & $\begin{array}{c}\text { Coliformes } \\
\text { Fecais } \\
(\mathbf{N M P / 1 0 0 m l})\end{array}$ & $\begin{array}{c}\text { Cloreto } \\
(\mathbf{m g} / \mathbf{L})\end{array}$ & $\mathbf{p H}$ & $\begin{array}{c}\text { CE } \\
(\boldsymbol{\mu} . \mathbf{S} / \mathbf{c m})\end{array}$ & $\begin{array}{c}\text { Turbidez } \\
(\mathbf{N T U})\end{array}$ & $\begin{array}{c}\text { Sólidos } \\
(\mathbf{m g} / \mathbf{L})\end{array}$ \\
\hline L. Santa Lúcia & $>16$ & 5,1 & 30,74 & 7,15 & 74 & 0,23 & 3,1 \\
L. Pio-X & 2,2 & 2,2 & 107,11 & 8,15 & 609 & 0,18 & 17,2 \\
L. Machado & 0,0 & 0,0 & 31,90 & 7,96 & 220 & 0,16 & 7,2 \\
L. Salete & $>16$ & 2,2 & 28,71 & 8,02 & 190 & 0,22 & 5,2 \\
L. São Paulo - 1 & 0,0 & 0,0 & 41,65 & 8,19 & 205 & 0,17 & 7,7 \\
L. São Paulo - 2 & 9,2 & 2,2 & 42,64 & 8,08 & 201 & 0,63 & 7,9 \\
L. Tiradentes & 0,0 & 0,0 & 36,00 & 8,78 & 242 & 0,49 & 8,0 \\
L. Navegantes & 0,0 & 0,0 & 61,49 & 8,51 & 474 & 0,49 & 14,1 \\
L. Santa Terezinha & $>16$ & 16 & 37,68 & 8,22 & 46 & 1,52 & 2,1 \\
L. Anta Gorda & 0,0 & 0,0 & 46,08 & 8,97 & 203 & 0,20 & 6,2 \\
\hline
\end{tabular}

Como são demonstrados na tabela os valores de coliformes totais e fecais variam de 0,0 a >16, mostrando uma variação muito grande entre os reservatórios coletados, a legislação CONAMA, considera água apropriada para o consumo quando há ausência de 
coliformes em $100 \mathrm{ml}$ de água, portanto, a água da maioria dos reservatórios não esta apropriada para o consumo segundo os resultados de coliformes totais e fecais.

$\mathrm{Na}$ Figura 3 são apresentados os resultados para coliformes totais. Como apresentado na Tabela 2, as fontes que apresentam coliformes em $100 \mathrm{ml}$ de água são: La. Santa Lúcia, La. Pio-X, La. Salete, Lạ. São Paulo 2, La. Santa Terezinha, sendo que nesta foram detectados os maiores índices.

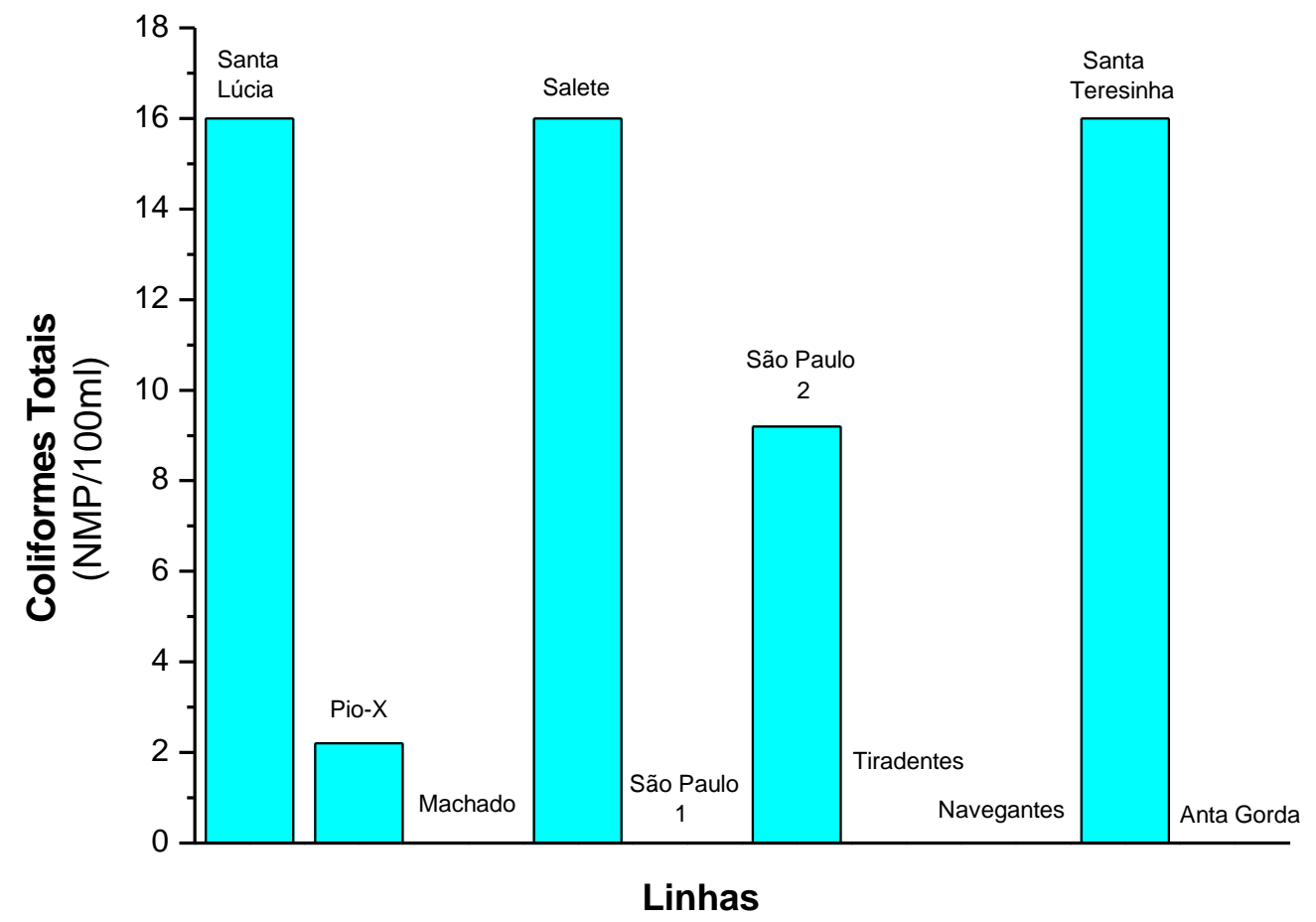

Figura 3. Contagem de Coliformes Totais para os 11 pontos de coleta.

A Figura 4 mostra os resultados obtidos nas análises para coliformes fecais, onde os pontos detectados foram: Lạ. Santa Lúcia, La. Pio-X, La. Salete, La . São Paulo 2, La․ Santa Terezinha, sendo que nesta foram detectados os maiores índices. 


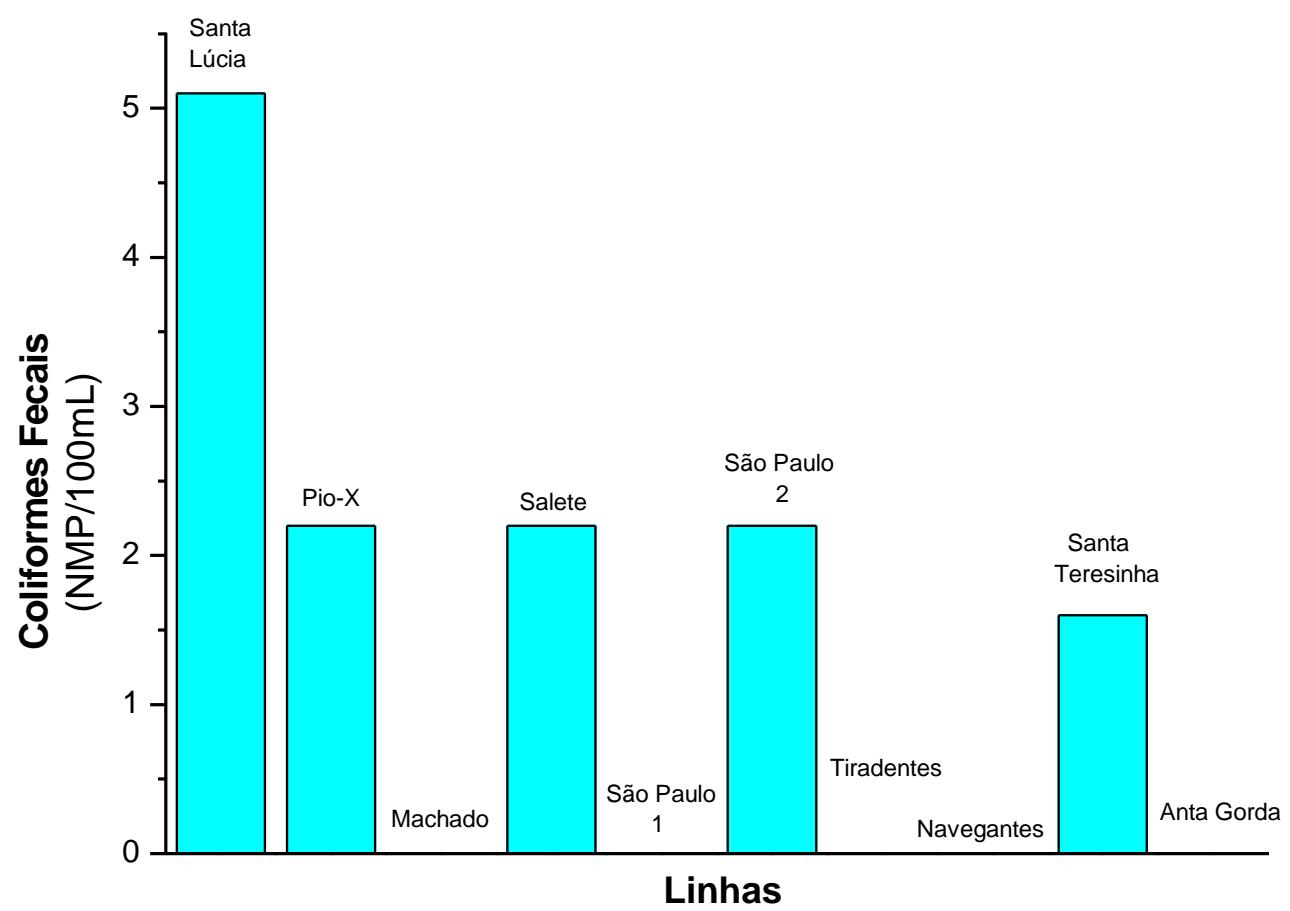

Figura 4. Contagem de Coliformes Fecais para os 11 pontos de coleta.

Os valores da concentração de cloreto na água também apresentam variância, segundo a legislação do CONAMA o máximo permitido de cloreto na água é de $250 \mathrm{mg} / \mathrm{L}$, os resultados obtidos variam entre $28,71 \mathrm{mg} / \mathrm{L}$ e $107,11 \mathrm{mg} / \mathrm{L}$, significando que todos os pontos estão dentro dos padrões.

A figura 5 apresenta os resultados para as concentrações de cloreto, sendo que todos os pontos estão dentro dos padrões estabelecidos. 


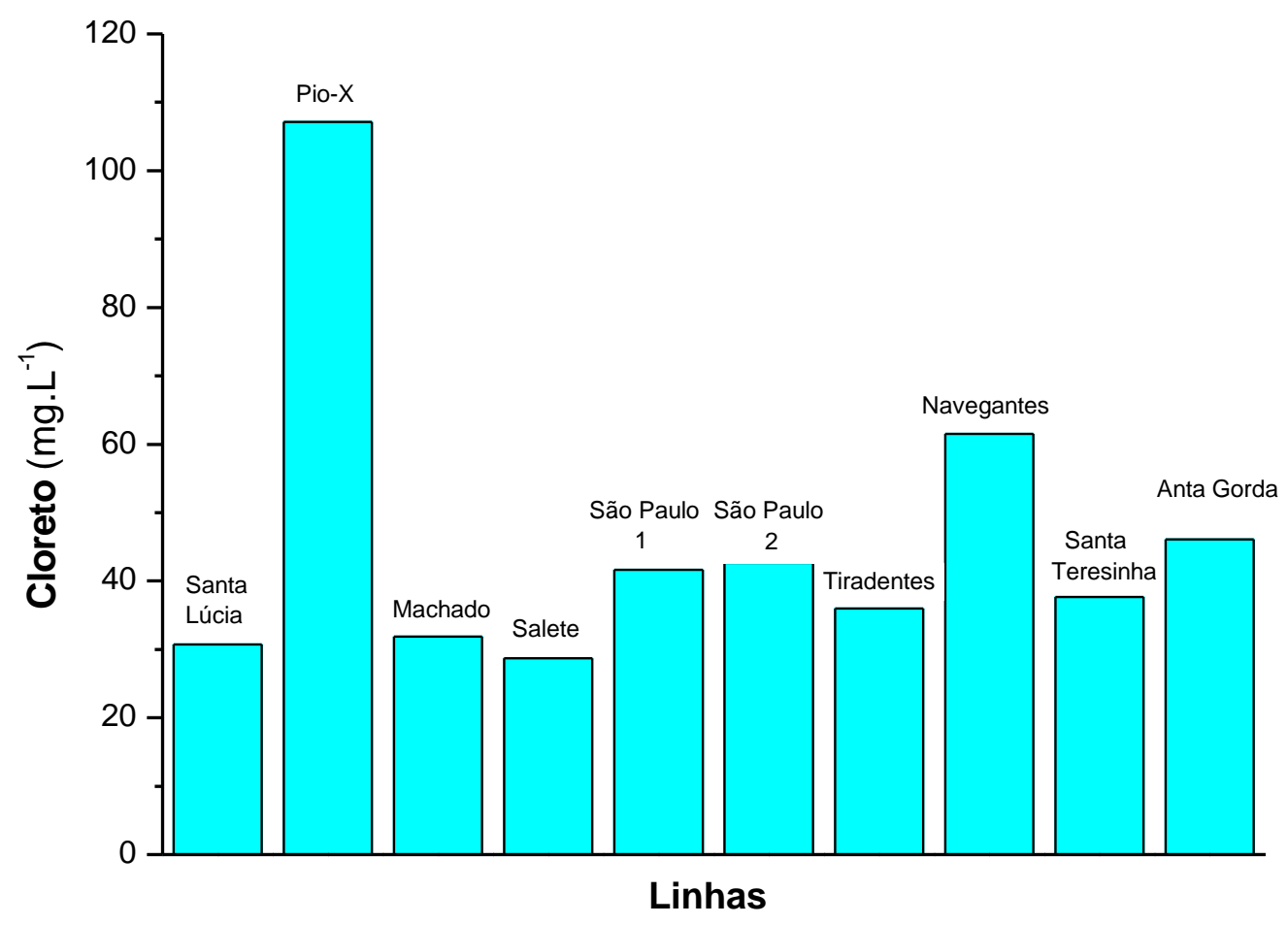

Figura 5. Medida da concentração do íon cloreto dos 11 pontos de coleta.

$\mathrm{Na}$ leitura do $\mathrm{pH}$, os valores obtidos não variam muito, encontrando-se todos dentro dos limites estabelecidos pelo CONAMA, que é de 6,5 à 9,5. O valor mínimo obtido foi de 7,15 e o máximo 8,97. Os valores de pH permitidos compreende um extensão muito ampla, portanto sua análise individual não permite conclusões muito segura.

Na figura 6 estão apresentados os valores obtidos pela análise do $\mathrm{pH}$. 


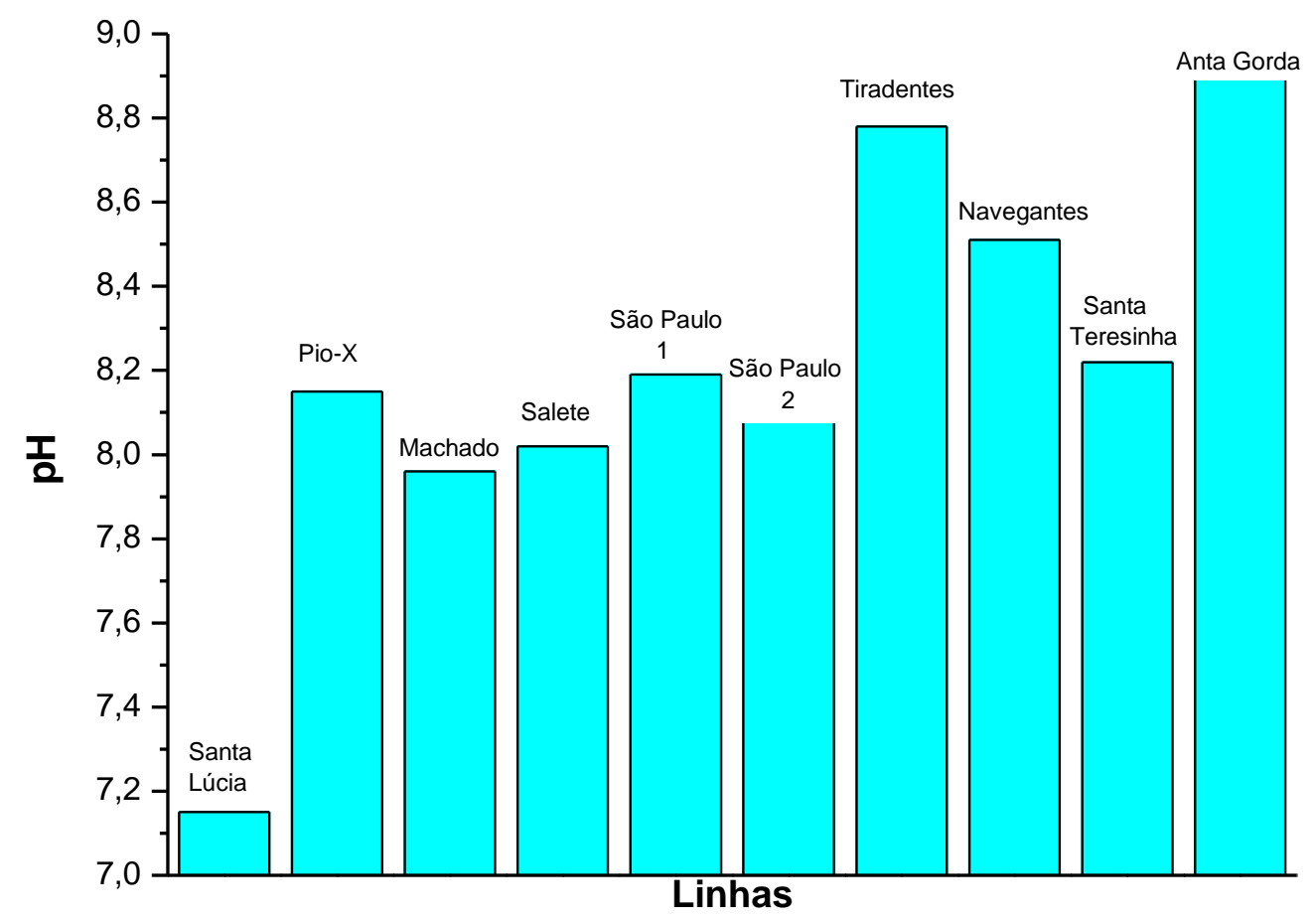

Figura 6. Medida do $\mathrm{pH}$ para os 11 pontos de coleta.

A condutividade elétrica apresentou grande diferença entre os pontos coletados, o máximo permitido segundo CONAMA é de $100 \mu \mathrm{S} / \mathrm{cm}$, podemos constatar que apenas 2 dos 11 pontos coletados estão dentro das exigências, os demais 9 apresentam valores bem elevados chegando a $609 \mu \mathrm{S} / \mathrm{cm}$ ( ponto 2, Linha Pio-X), o que pode estar relacionado com a concentração de poluentes, cloretos por exemplo, pois depende da concentração iônica da água. A condutividade também fornece uma indicação da concentração mineral, mas não especifica as quantidades relativas destes componentes.

A figura 7 apresenta os resultados para a condutividade elétrica. 


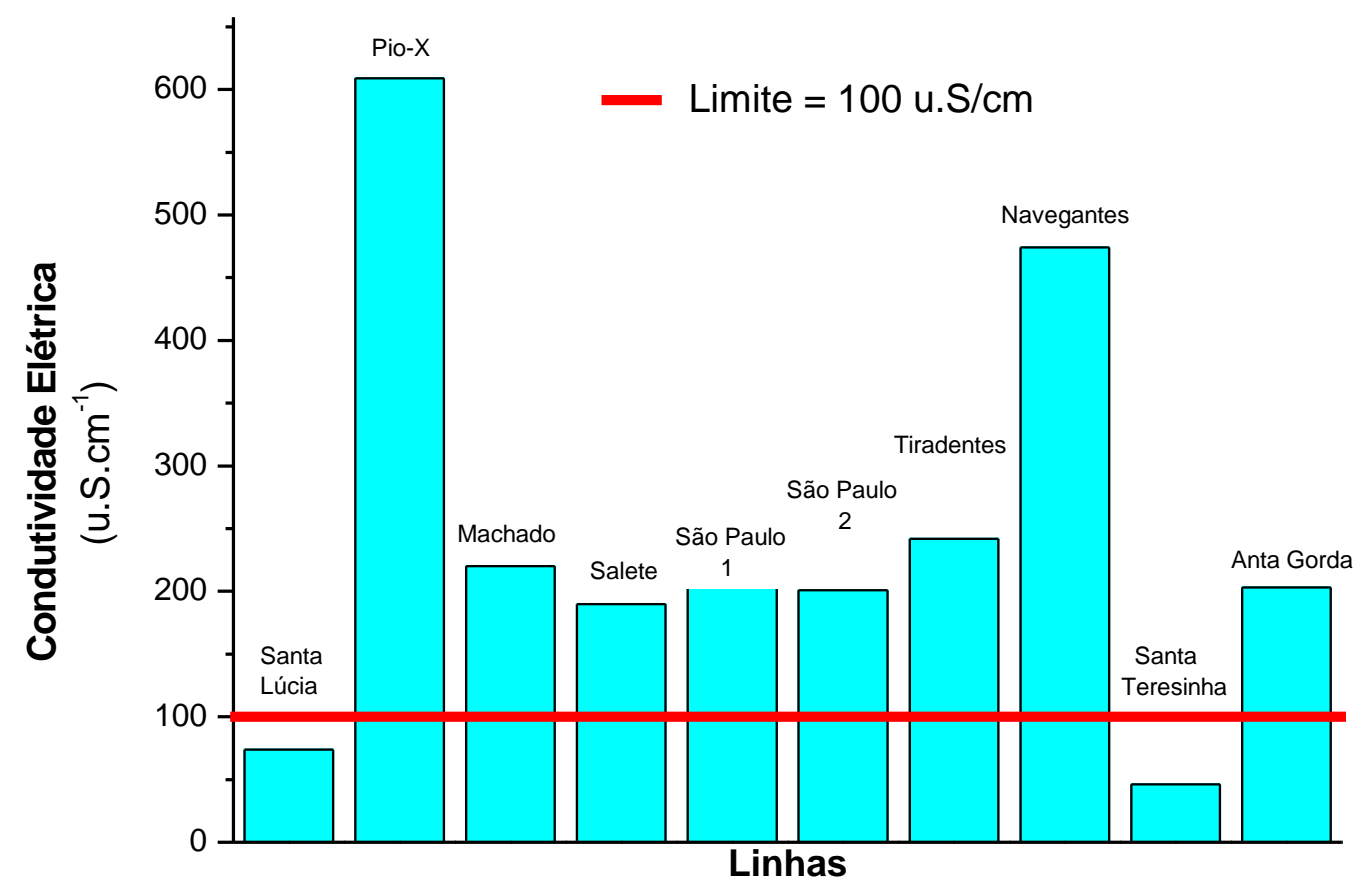

Figura 7. Condutividade Elétrica para os 11 pontos de coleta.

A turbidez, segundo CONAMA não deve ultrapassar 1,0 UNT (unidade nefelométrica de turbidez), a Tabela 2 mostra que apenas a fonte 09 (L. Santa Terezinha) não atende as normas, apresentando uma turbidez de 1,52 NTU, esse índice é devido à presença de sólidos em suspensão, detritos orgânicos, bactérias Uma possível explicação está na origem de captação desta água, uma vez que, esta água tem uma captação menos profunda que as demais.

A figura 8 mostra os valores obtidos pela leitura da turbidez. 


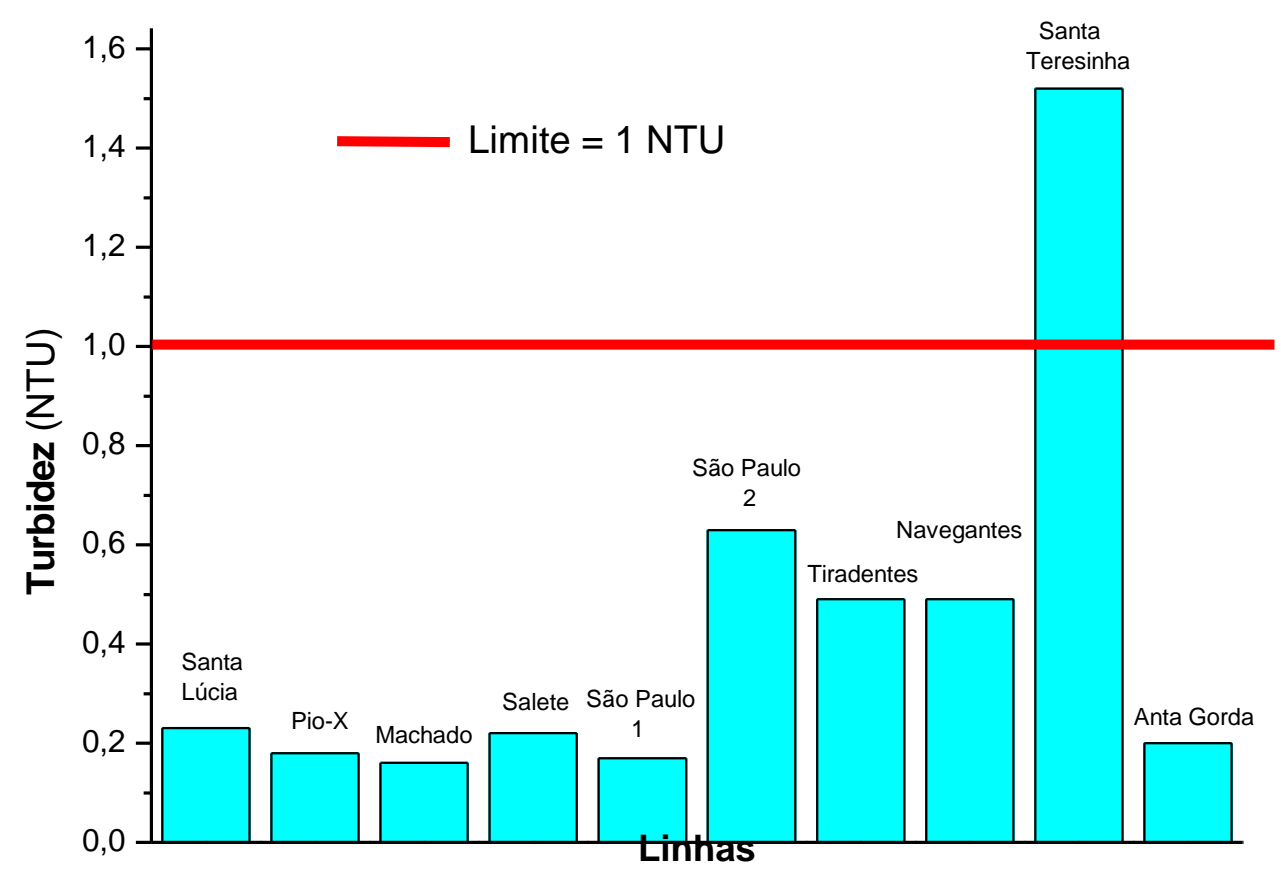

Figura 8. Medida de Turbidez para os 11 pontos de coleta.

A quantidade máxima de sólidos permitida pelo CONAMA é de $500 \mathrm{mg} / \mathrm{L}$. Na figura 9 estão apresentados os resultados obtidos para sólidos, que mostram uma variação de $2,1 \mathrm{mg} / \mathrm{L}$ a $17,2 \mathrm{mg} / \mathrm{L}$, portanto todos os pontos coletados estão dentro da faixa permitida. 


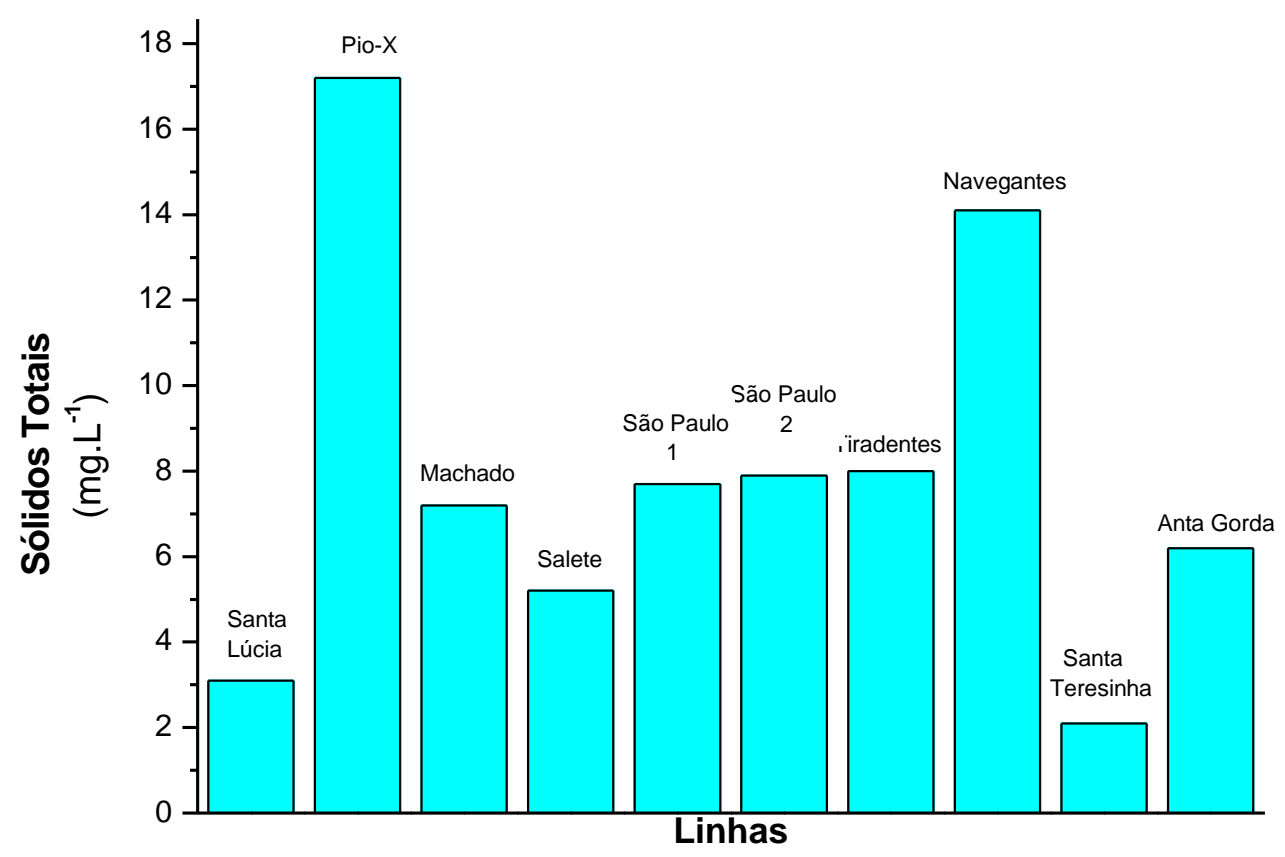

Figura 9. Medida de Sólidos Totais para os 11 pontos de coleta.

\section{CONCLUSÃo}

Foram analisadas águas dos reservatórios comunitários do perímetro rural da cidade de Pinhalzinho/SC. Com os resultados obtidos conclui-se que todas as fontes estão apresentando características que as tornam impróprias para o consumo, sendo que a fonte 9- Linha Santa Terezinha apresenta a maior quantidade de resultados fora dos padrões, porém, todas elas necessitam desse modo um tratamento adequado.

\section{REFERÊNCIAS}

CAMPONOGARA, S. Saúde e meio ambiente na contemporaneidade: O necessário resgate do legado de Florence Nightingale. Ed. Esc. Anna Nery, 2012, v.16, n.1, p.178184. 
CONSELHO NACIONAL DO MEIO AMBIENTE - CONAMA. Resolução no $\mathbf{3 5 7}$ de $\mathbf{1 7}$ de março de 2005. Dispõe sobre a classificação dos corpos de água e diretrizes ambientais para o seu enquadramento, bem como estabelece as condições e padrões de lançamento de efluentes. Ministério do Meio Ambiente, 2005. Disponível em:

< http://www.mma.gov.br/port/conama/legiano1.cfm?codlegitipo=3\&ano=2005>. Acesso em: 21 set. 2012.

FUNASA. Fundação Nacional de saúde. Manual Prático de Análise de Água. Acessoria de comunicação e educação em saúde. Brasília-DF. Disponível em: <www.funasa.gov.br> Acesso em: 24 fev. 2012.

MAYER, D. A. et al. Estudo comparativo do fluxo químico hidrológico em diferentes áreas no município de Pinhalzinho. In: Congresso de iniciação científica e pósgraduação, 2010, Florianópolis-SC. Graduação, 2010, v.1, p. 60-61.

RICHTER, C. T. Tratamento de água: Tecnologia Atualizada. Ed. Edgard Blucher, São Paulo, 2003.

SOUZA, S. A. de. Água juridicamente sustentável: Um estudo sobre a educação ambiental como instrumento de efetividade do programa de conservação e uso racional da água nas edificações de Curitiba/PR. Revista Meio Ambiente e Sustentabilidade, v. 1, n. 1, 2012. 